\title{
S-WAVE SPECTRAL ANALYSIS AND ESTIMATION OF SPECTRAL PARAMETERS IN NORTHWESTERN GREECE
}

\author{
Stavroulopoulou O. ${ }^{1}$, Sokos E. ${ }^{1}$ and Tselentis G.-A. ${ }^{1}$ \\ 'University of Patras, Faculty of Geology, Seismological Laboratory, ostavrol@upatras.gr, \\ esokos@upatras.gr,tselenti@upatras.gr
}

\begin{abstract}
During a 12-month period (August 1998 - June 1999), a dense microseismic network of 44 portable seismographs, was installed in Epirus - Northwestern Greece, by the Seismological Laboratory, of the University of Patras and recorded 1368 earthquakes. We selected a subset of 200 well recorded events, with duration magnitude ranging from 1.61 to 2.92 and focal depths ranging from a few hundred meters to $35 \mathrm{~km}$; the majority was in the $0-10 \mathrm{~km}$ range. This study uses this high quality dataset to (i) calculate the earthquake spectra and source parameters; (ii) perform linear regression between Seismic Moment $\left(M_{0}\right)$ and the source parameters Source Radius (r), Stress Drop $(\Delta \sigma)$ and Displacement (s); (iii) correlate source parameter's distribution with the tectonics of the area. Finally, we compare the derived empirical laws with similar studies.

Keywords: Microseismicity, source parameters, Epirus, stress drop, Brune model.

\section{Пєрі́ $\eta \psi \eta$}

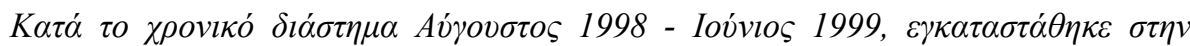

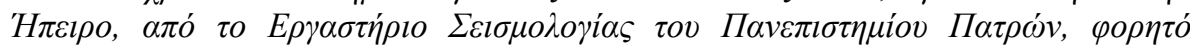

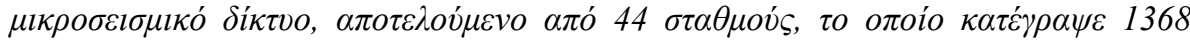

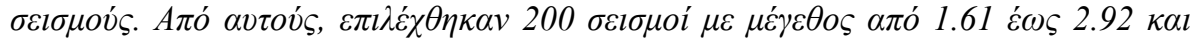

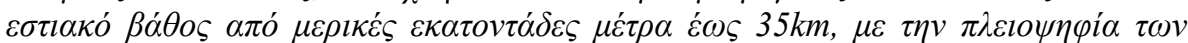

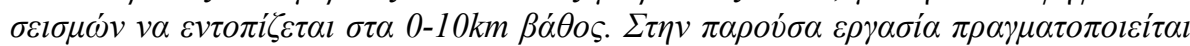

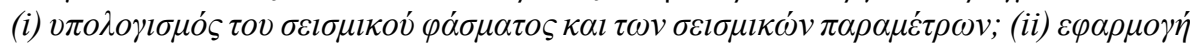

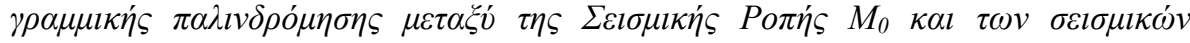

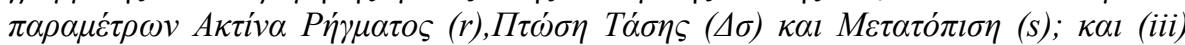

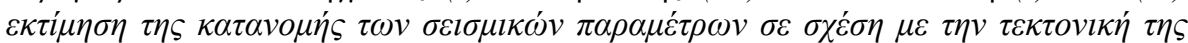

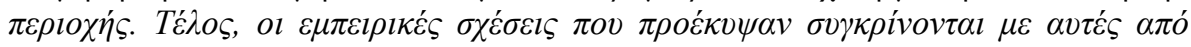

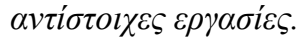

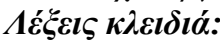

\section{Introduction}

The estimation of source parameters is a critical task in seismology and can be accomplished with various methodologies. This study uses high quality data in order to (i) calculate spectral parameters of earthquake source, namely low frequency displacement spectral level $\left(\Omega_{0}\right)$, corner frequency (fc), cut-off frequency above which the acceleration spectra shows a sharp decrease with increasing frequency (fmax) (Boore, 1983) and the rate of decay above fmax (N); (ii) estimate source parameters namely seismic moment $\left(\mathrm{M}_{0}\right)$, source radius $(\mathrm{r})$, stress drop $(\Delta \sigma)$ and displacement (s) 
for each earthquake; (iii) develop a linear regression of the source parameters and (iv) correlate the source parameters distribution with the tectonic characteristics of the region.

Epirus extends from the Ionian Sea and belongs to External Hellenides, where three isopic zones, are formed. Starting from the eastern end, the Pindos zone is thrusted on the Gavrovo zone and the latter on the Ionian zone (Avramidis et al., 2000; Kiratzi et al., 1987; Waters, 1994; Hatzfeld et al., 1995), performed microearthquake studies in Epirus, which have shown an ENE-WSW shortening which agrees with the continental convergence west of Corfu and a NNW extension, close to the Pindos foothills, further east. Taymaz et al. (1991), asserted that the E-W shortening generates thrust belts that trend N-NW and are cut by almost perpendicular strike slip or normal faults. King et al. (1983), based on a boundary-element model proposed a substantial left lateral strike-slip component in addition to the compressional motion. In agreement with this idea are the results of the geological and geomorphological research performed by IGSR and IFP (1966) and King et al. (1993) and the crustal deformation study of the Aegean area performed by Papazachos and Kiratzi (1996). At the Epirus area the extensional inner Aegean regime switches to the compressional outer Aegean. According to Hatzfeld et al. (1995), the compressional regime in Epirus is caused by the jump of active thrusting from the Pindos to the Ionian zone, which is still active at the present time. The focal mechanisms from earthquakes located in Epirus, denote thrust and strike slip to normal geological structures (Mercier et al., 1972; King et al., 1983; Doutsos et al., 1987; Underhill, 1989; Waters, 1994; Hatzfeld et al., 1995). Additional information derived from Martakis (2003), Tselentis et al. (2006) and Stavroulopoulou et al. (2013) seismotectonic studies in Epirus, agree with a thrust belt zone at the west, combined with an extensional regime at the eastern end.

In this article, we analysed earthquake source spectra calculated from high quality seismological data from the area of Epirus, in order to estimate the spectral parameters and correlate them with the tectonics of the area.

\section{Seismograph Network and Data}

For this study, we used high quality seismological data, which were recorded during a 12-month period (August 1998 - June 1999) by a dense microseismic network of 44, three component portable seismographs. During the aforementioned 12-month operation period 1368 earthquakes were recorded.

From this dataset, 200 well recorded events, which were relocated within the area of interest from Stavroulopoulou et al. (2013), were selected and analysed in this paper. The duration magnitude of this subset ranges from 1.61 to 2.92 and the focal depth ranges from a few hundred meters to $35 \mathrm{~km}$. The majority of focal depths were in the $0-10 \mathrm{~km}$ range. In the same study of Stavroulopoulou et al. (2013), the area was divided into ten clusters of events based on their spatial distribution. The spectrum analysis was applied per cluster, in order to correlate the estimated source parameters with the seismotectonic characteristics of each smaller structural area (cluster), extending the work of Stavroulopoulou et al. (2013). 


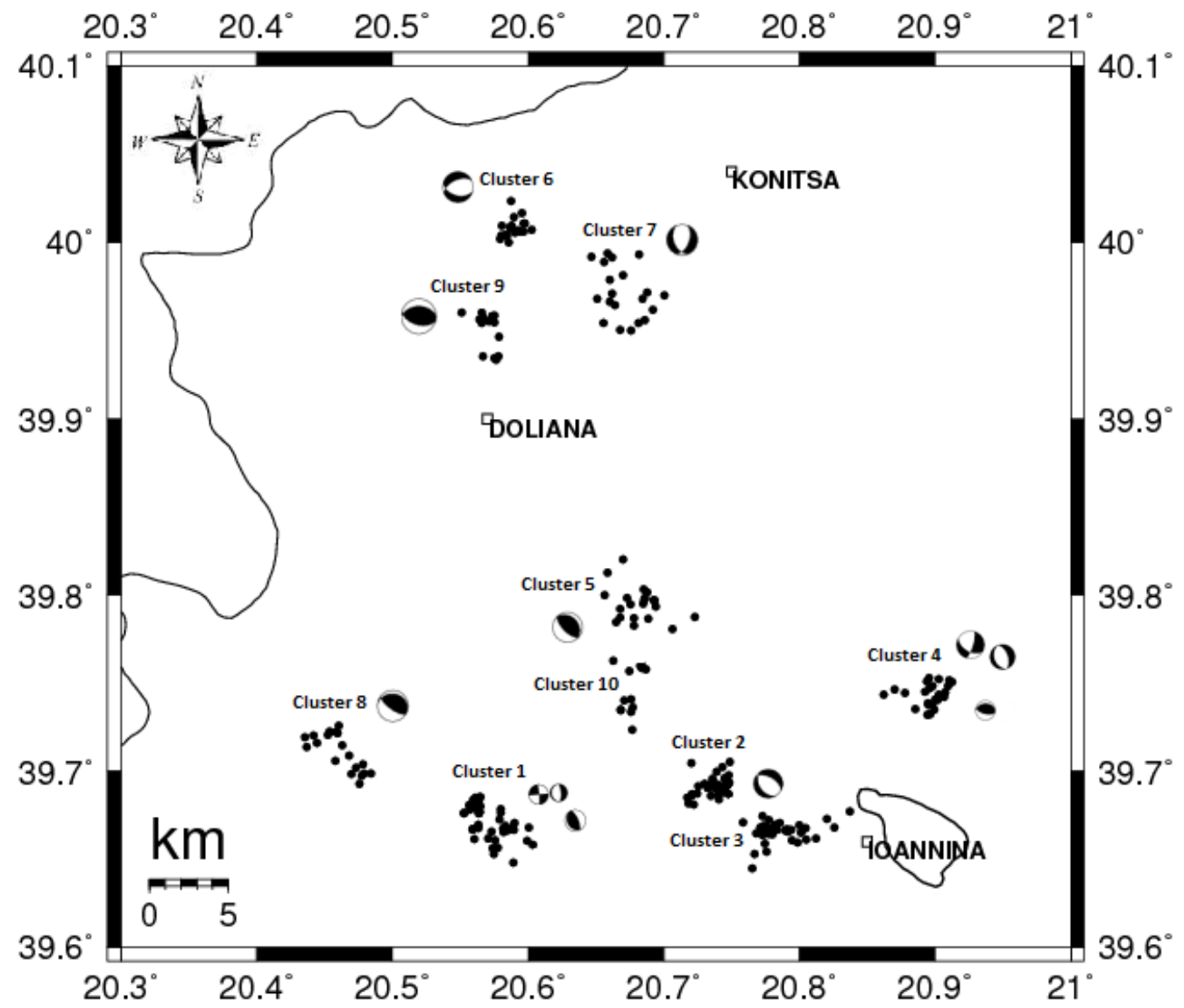

Figure 1 - The distribution of the 200 relocated epicentres for which source parameters were determined and the representative focal mechanisms of each cluster (Stavroulopoulou et al., 2013).

\section{Method of analysis}

To estimate earthquake spectral and source parameters, the EQK_SRC_PARA software was applied, (Kumar et al., 2012). The time histories are first corrected for instrument response using the transfer function and then rotated according to their azimuth to obtain the SH-component of ground motion. EQK_SRC_PARA is performing the spectral analysis on the SH-component. Spectrum is obtained from Fast Fourier Transform and is corrected for attenuation due to path. The software EQK_SRC_PARA, automatically picks the spectral parameters, (i) low frequency displacement spectral level $\left(\Omega_{0}\right)$, (ii) corner frequency (fc), (iii) the (fmax) frequency and (iv) the rate of decay above fmax $(\mathrm{N})$. For the calculation of seismic moment $\left(\mathrm{M}_{0}\right)$ value, the Brune's source model was assumed, (Brune, 1970, 1971).

The values of the source parameters are estimated using the following equations:

Equation 1 - Seismic Moment $\left(\mathrm{M}_{0}\right)$ for the $\mathrm{S}$ seismic waves, (Brune, 1970, 1971):

$$
M o=\frac{4 \pi \rho \beta^{3} R \Omega_{0}}{R_{\theta \varphi} S_{\alpha}}
$$


Where $\rho$ is the average density $\left(=2.67 \mathrm{~g} / \mathrm{cm}^{3}\right), \beta$ is shear wave velocity in the source zone $(=3.2$ $\mathrm{km} / \mathrm{s}), \mathrm{R}$ is the hypocentral distance, $\mathrm{R}_{\theta \varphi}$ is the average radiation pattern $(=0.63), \mathrm{S} \alpha$ is free surface amplification $(=2)$.

Equation 2 - Moment Magnitude (Mw):

$M_{W}=\frac{2}{3} \log \left(M_{0}\right)+10.7$

Equation 3 - Source Radius (r), (Brune, 1970):

$$
r=\frac{2.34 \beta}{2 \pi f_{c}}
$$

Equation 4 - Stress Drop $(\Delta \sigma)$, (Keilis-Borok, 1959; Kanamori and Anderson, 1975):

$$
\Delta \sigma=\frac{7 M_{o}}{16 r^{3}}
$$

Equation 5 - Displacement (s), (Brune, 1968):

$$
s=\frac{M_{o}}{\mu \pi r^{2}}
$$

A time window over the S-wave is selected and a standard Fourier spectral analysis is applied. In order to determine the best duration for the $\mathrm{S}$-wave window, several tests with different durations were performed. The time window duration with the most robust results was $2.5 \mathrm{sec}$.

The S-wave log-displacement spectrum is divided in two sections: (i) a flat section with amplitude level $\Omega_{0}$ up to a frequency fc, and (ii) a roll-off linear decay. On the displacement spectrum, two intersecting lines are defined optically, which determine the source characteristics of each event analysed: (i) the overall mean trend of the low-frequency spectral asymptote and (ii) the highfrequency roll-off. (Brune et al., 1986; Melis, 1992; Burton et al., 1995).

An example of the analysis is shown in Figure 6 and Figure 3 taken from the March $7^{\text {th }} 1999$, 10:10:00 UTC, earthquake.

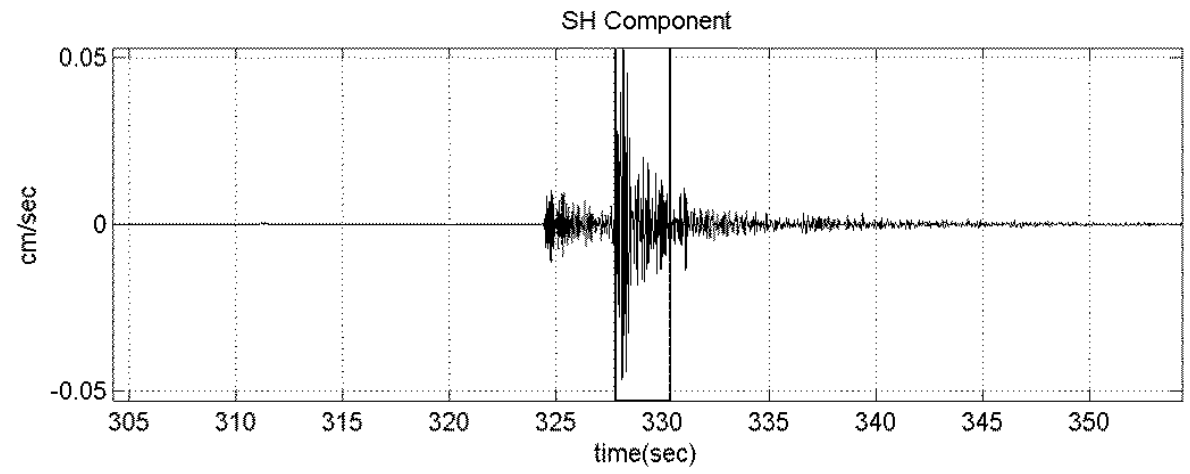

Figure 2 - The selected time window over the S-wave, for the March $7^{\text {th }}$, 1999, 10:10:00 UTC, earthquake. 


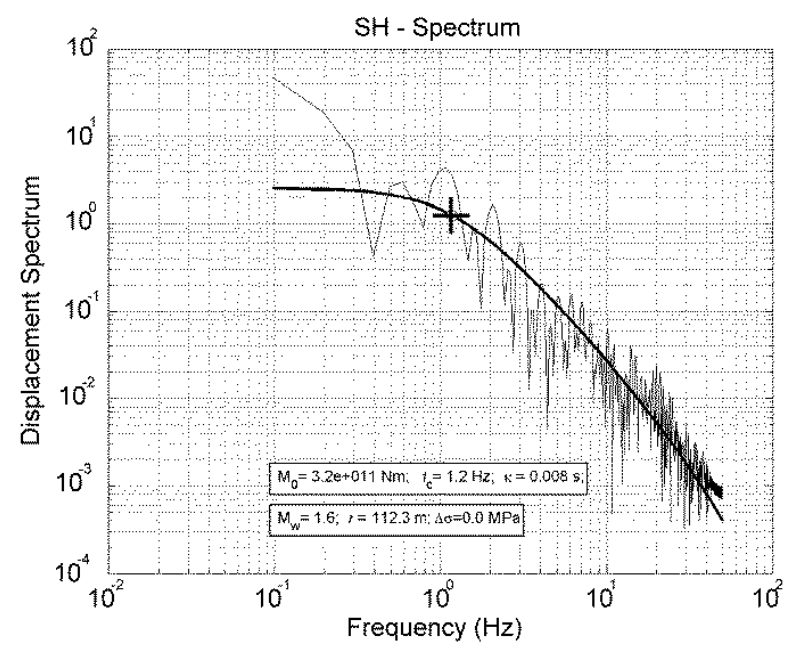

Figure 3 - The displacement spectrum for the March $7^{\text {th }} 1999,10: 10: 00$ UTC, earthquake. Cross symbol defines fc; thin line represents the displacement spectrum; thick line represents the fitted Brune spectrum.

\section{Results of the spectral analysis}

In the following paragraphs we discuss in detail the results of the $\mathrm{S}$-wave spectral analysis obtained within each cluster and the relationship between seismic moment $\left(\mathrm{M}_{0}\right)$ and the source parameters, source radius $(\mathrm{r})$, stress drop $(\Delta \sigma)$ and displacement (s), in order to investigate crustal deformation in Epirus.

Totally, 200 events were analysed and the range of the values of the source parameters determined are shown in Table 1:

Table 1 - Range of the seismic parameter's values.

\begin{tabular}{|c|c|c|c|c|c|c|c|c|c|c|c|c|c|}
\hline \multirow{2}{*}{$\begin{array}{c}\text { Cluster } \\
\text { No }\end{array}$} & \multirow{2}{*}{ Events } & \multicolumn{2}{|c|}{$\mathrm{Mo}(\mathrm{Nm})$} & \multicolumn{2}{|c|}{$r(m)$} & \multicolumn{2}{|c|}{$\Delta \sigma$ (bars) } & \multicolumn{2}{|c|}{$\mathrm{s}(\mathrm{mm})$} & \multicolumn{2}{|c|}{$\Omega \circ(\mathrm{cm})$} & \multicolumn{2}{|c|}{ fc $(\mathrm{Hz})$} \\
\hline & & $\min$ & $\max$ & $\min$ & $\max$ & $\min$ & $\max$ & $\min$ & $\max$ & $\min$ & $\max$ & $\min$ & $\max$ \\
\hline 1 & 34 & $6,0 \mathrm{E}+10$ & $8,2 E+12$ & $8,5 E+01$ & $1,6 \mathrm{E}+02$ & $3,4 E-01$ & $9,2 E+00$ & $7,58 \mathrm{E}-02$ & $3,25 E+00$ & $7,5 E^{2}-05$ & $5,7 \mathrm{E}-03$ & 7,95 & 15,3 \\
\hline 2 & 30 & $2,2 E+11$ & $4,8 \mathrm{E}+12$ & $1,3 E+02$ & $3,1 E+02$ & $1,7 E-01$ & $1,1 E+00$ & $7.51 \mathrm{E}-02$ & $6,00 \mathrm{E}-01$ & $1,4 E-04$ & $1,9 \mathrm{E}-03$ & 4,2 & 9,75 \\
\hline 3 & 30 & $1,1 E+11$ & $1,7 E+12$ & $9,5 E+01$ & $3,7 \mathrm{E}+02$ & $8,6 \mathrm{E}-02$ & $1,6 E+00$ & $3,92 \mathrm{E}-02$ & $5,12 \mathrm{E}-01$ & $9,0 E-05$ & $8,0 \mathrm{E}-04$ & 3,5 & 13,7 \\
\hline 4 & 14 & $6,0 E+10$ & $6,3 E+13$ & $7,8 E+01$ & $3,9 E+02$ & $8,2 E-02$ & $2,6 E+01$ & $3,92 \mathrm{E}-02$ & $1,85 E+01$ & $2,7 E-04$ & $1,5 \mathrm{E}-02$ & 5,2 & 11,4 \\
\hline 5 & 18 & $2.1 E+11$ & $7,1 E+12$ & $9,1 E+01$ & $1,9 E+02$ & $6,3 E-01$ & $1,7 E+01$ & 1,16E-01 & $5,03 E+00$ & $1,8 E-04$ & $6,7 \mathrm{E}-03$ & 6,8 & 14,4 \\
\hline 6 & 19 & $4,0 \mathrm{E}+11$ & $2,4 E+13$ & $9,8 E+01$ & $2,6 \mathrm{E}+02$ & 5, $1 \mathrm{E}-01$ & $2,5 E+01$ & $1,04 \mathrm{E}-01$ & $5,27 \mathrm{E}+00$ & $2,3 E-04$ & 1,1E-02 & 5,1 & 13,3 \\
\hline 7 & 15 & $1,7 E+11$ & $5,9 E+12$ & $1,0 E+02$ & $2,3 E+02$ & $2,9 E-01$ & $6,1 E+00$ & $7,87 \mathrm{E}-02$ & $2,25 E+00$ & $1,3 E-04$ & $3,4 \mathrm{E}-03$ & 5,8 & 12,6 \\
\hline 8 & 13 & $9,8 \mathrm{E}+10$ & $8,5 E+12$ & $8,0 E+01$ & $1,7 \mathrm{E}+02$ & $3,9 \mathrm{E}-01$ & $9,7 E+00$ & $1,21 \mathrm{E}-01$ & $4,20 \mathrm{E}+00$ & 1,4E-04 & 6,7E-03 & 7,7 & 16,2 \\
\hline 9 & 15 & $1,7 E+11$ & $1,6 \mathrm{E}+13$ & $1,0 E+02$ & $2,2 E+02$ & $6,5 \mathrm{E}-01$ & $6,7 E+00$ & $1,61 \mathrm{E}-01$ & $3,50 \mathrm{E}+00$ & $1,8 \mathrm{E}-04$ & $8,4 \mathrm{E}-03$ & 5,9 & 12,5 \\
\hline 10 & 12 & $1,2 E+11$ & $2,6 \mathrm{E}+12$ & $9,4 E+01$ & $1,4 \mathrm{E}+02$ & $2,8 \mathrm{E}-01$ & $1,1 E+01$ & $1,20 \mathrm{E}-01$ & $3,17 \mathrm{E}+00$ & $1,3 E-04$ & $3,2 \mathrm{E}-03$ & 9,1 & 13,9 \\
\hline$A L L$ & 200 & $6.0 E+10$ & $6,3 E+13$ & $7,8 E+01$ & $3,9 E+02$ & $8,2 E-02$ & $2,6 E+01$ & $3,9 \mathrm{E}-02$ & $1,8 E+01$ & $7,5 E-05$ & $1,5 E-02$ & 3.5 & 16.2 \\
\hline
\end{tabular}

Pairs of $\left(\log \mathrm{M}_{0}-\log \right),\left(\log \mathrm{M}_{0}-\log \Delta \sigma\right)$ and $\left(\log \mathrm{M}_{0}-\log s\right)$ values were analysed for the 10 cluster subsets and for the whole data set. Since the derived regression laws, per cluster, were similar we will discuss the results for the whole dataset only. The regression coefficients obtained using the whole data set, are presented in Table 2: 
Table 2 - Regression of source parameters for the whole dataset.

\begin{tabular}{|c|c|c|c|c|c|}
\hline \multicolumn{2}{|c|}{ Regression $\left(\mathrm{M}_{0}-\mathrm{r}\right)$} & \multicolumn{2}{|c|}{ Regression $\left(\mathrm{M}_{0}-\Delta \sigma\right)$} & \multicolumn{2}{|c|}{ Regression ( $\left.\mathrm{M}_{0}-\mathrm{s}\right)$} \\
\hline Equation & $R^{\wedge} 2$ & Equation & $R^{\wedge} 2$ & Equation & $R^{\wedge} 2$ \\
\hline $\log M o=1,85 \log r+7,89$ & 0,20 & $\log M o=0,76 \log \Delta \sigma+11,86$ & 0,46 & $\log M_{0}=0,97 \log s+12,29$ & 0,77 \\
\hline
\end{tabular}
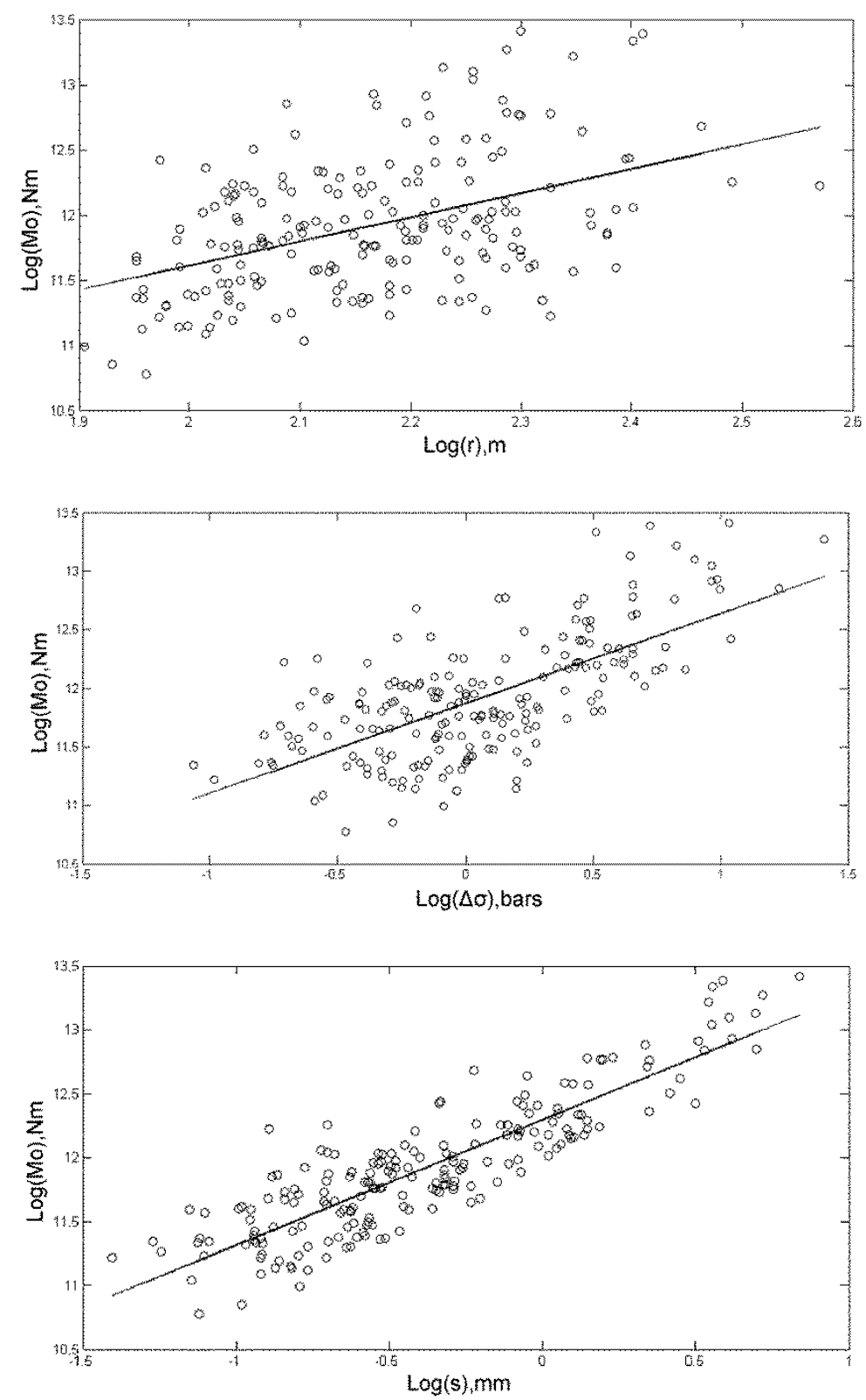

Figure 4 - Linear regression between seismic moment $\left(M_{0}\right)$ and source radius $(r)$, stress drop $(\Delta \sigma)$ and displacement $(s)$, for the whole data set.

The relationship between seismic moment $\left(\mathrm{M}_{0}\right)$ and displacement (s) was quite strong for almost all of the clusters, with the $\mathrm{R}^{2}$ equal 0.77 for the case of whole dataset. Similarly, the relationship 
between seismic moment $\left(\mathrm{M}_{0}\right)$ and stress drop $(\Delta \sigma)$ was moderate, with the median of $\mathrm{R}^{2}$ equal 0.46 Furthermore, the values of stress drop are low, ranging from 0.1 bars to 25.4 bars, which is in agreement with the low stress drop character of Greek earthquakes (Kiratzi et al., 1985). The relationship between seismic moment $\left(\mathrm{M}_{0}\right)$ and source radius $(\mathrm{r})$, was quite poor, with $\mathrm{R}^{2}$ equals 0.20 for the whole dataset.

The stress drop variation with moment and source radius is examined in Fig.4. Seismic moment (Mo) versus source radius (r) values for the whole dataset, are plotted with lines of constant stress drop determined from Equation 4. A linear dependence between seismic moment (Mo) and source radius (r) is observed, for the studied moment and source radius range, suggesting constant stress drop.

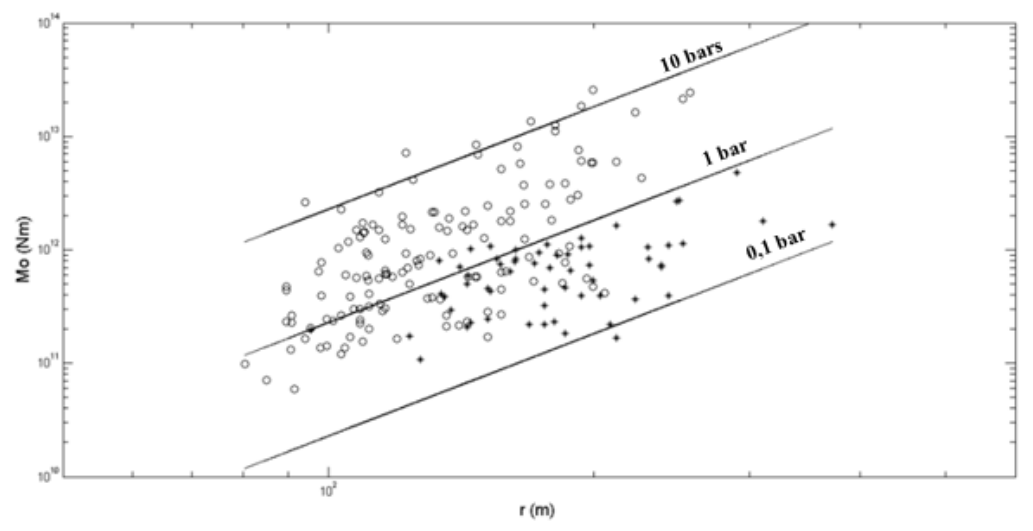

Figure 5 - Seismic moment versus source radius. Star symbols indicate values from cluster 2 and cluster 3; circle symbols indicate the other clusters. Lines of constant stress drop determined from Equation 4, are also indicated.

Specifically, cluster 2 and cluster 3 which are located west of Ioannina, show very poor correlation between the calculated source parameters. This area was referred by King et al. (1993) as Ioannina basin and is located over an evaporate dome (Tselentis et al., 2006). The majority of the earthquakes, which were used for the spectral analysis, occurred at shallow depths up to $5 \mathrm{~km}$. This special characteristic of these events, which separate them from the whole dataset, lead us to remove these clusters from the analysis. Omitting cluster 2 and cluster 3 from the regression produced a significant improvement in the regression analysis, between the source parameters, as shown in Table 3:

Table 3 - Regression from the whole dataset omitting cluster 2 and cluster 3.

\begin{tabular}{|c|c|c|c|c|c|}
\hline \multicolumn{2}{|c|}{ Regression $\left(M_{0}-r\right)$} & \multicolumn{2}{|c|}{ Regression $\left(\mathrm{M}_{0}-\Delta \sigma\right)$} & \multicolumn{2}{|c|}{ Regression ( $\mathrm{M}_{0}$-s) } \\
\hline Equation & $R^{\wedge} 2$ & Equation & $R^{\wedge} 2$ & Equation & $R^{\wedge} 2$ \\
\hline $\log M o=3,38 \log r+4,79$ & 0,43 & $\log M o=1,11 \log \Delta \sigma+11,7$ & 0,60 & $\log M o=1,16 \log s+12,26$ & 0,87 \\
\hline
\end{tabular}

\section{Conclusions - Discussion}

In this paper we present empirical relations of source parameters using a high quality dataset from Epirus. A dataset of 200 events was analysed using an S-wave spectral fitting technique and Brune model, to estimate seismic moment, stress drop, displacement and source radius. The initial dataset was divided in ten clusters according to seismotectonic characteristics of the area (Stavroulopoulou et al., 2013). Then, the regression analysis was applied to each cluster and to the whole dataset separately. The calculated moment magnitude for the whole dataset ranges from 1.2 to 2.9. Since the regression results were similar among the examined clusters, we restrict our analysis to the whole dataset only. The spectral analysis provided a quite good correlation between seismic moment and 
displacement and a moderate correlation between seismic moment and stress drop, for most of the clusters and for the whole dataset. The poor correlation obtained between seismic moment and source radius precludes its further use. In the Ioannina Basin area (clusters 2 and 3), the very poor correlation between the calculated source parameters is probably due to the shallow depth of the seismicity. This seismicity is connected with the presence of an evaporite body in the area (Tselentis et al., 2006).
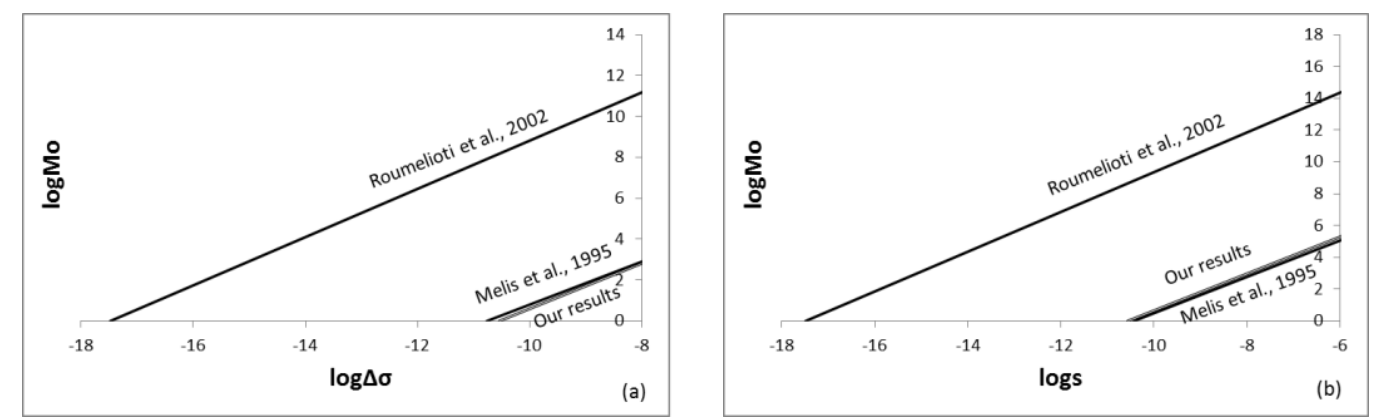

Figure 6 - Comparison between a) seismic moment $\left(M_{0}\right)$ and stress drop $(\Delta \sigma)$ and b) seismic moment (Mo) and displacement (s), proposed by Roumelioti et al., 2002; Melis et al., 1995; and our results omitting cluster 2 and cluster 3.

A comparison of the empirical laws derived in this study, for Epirus (Table 3), with the ones proposed by Roumelioti et al. (2002) and Melis et al. (1995) for Kozani and Corinth gulf respectively is presented in Fig. 6. The magnitude range examined in Roumelioti et al. (2002) was the highest $\left(\sim 3-4.5 \mathrm{M}_{\mathrm{L}}\right)$, while the datasets of this paper and Melis et al. (1995) are comparable in magnitude range $\left(\sim 1.5-3.5 \mathrm{M}_{\mathrm{L}}\right)$. The empirical laws derived in this study, are very close to Melis $e t$ al. (1995) and depict a similarity with Roumelioti et al. (2002).

\section{Acknowledgments}

The first author thanks Dr. Vasilis N. Nikolaidis and Dr. Paraskevas Paraskevopoulos for their assistance in software development and use.

\section{References}

Avramidis, P., Zelilidis, A. and Kontopoulos, N., 2000. Thrust dissection control of deep-water clastic dispersal patterns in the Klematia - Paramythia foreland basin, western Greece, Geol. Mag., 137(6), 667-685.

Boore, D.M., 1983. Stochastic simulation of high-frequency ground motions based on seismological models of the radiated spectra, Bulletin of the Seismological Society of America, 73(6A), 1865-1894.

Brune, J.N., 1968. Seismic moment, seismicity, and the rate of slip along major fault zones, $J$. Geophys. Res., 73, 777-789.

Brune, J.N., 1970. Tectonic stress and the spectra of seismic shear waves from earthquakes, $J$. Geophys. Res., 75, 4997-5009.

Brune, J.N., 1971. Corrections, J. Geophys. Res., 76, 5002.

Brune, J.N., Fletcher, J.B., Vernon, F.L., Haar, L., Hanks, T.C. and Berger, J., 1986. Low stressdrop earthquakes in the light of new data from the Anza, California telemetererd digital array, Earthquake Source Mechanics, AGU Monograph, 37, 237-245.

Burton, P.W., Melis, S.N. and Brooks, M., 1995. Coseismic crustal deformation on a fault zone defined by microseismicity in the Pavliani area, central Greece, Geophys. J. Int., 123, 16-40.

Doutsos, T., Kontopoulos, N. and Fridas, D., 1987. Neotectonic evolution of northwestern continental Greece, Basin Res. 1, 177-190. 
Hatzfeld, D., Kassaras, L., Panagiotopoulos, D., Amorese, D., Makropoulos, K., Karakaisis, G. and Coutand, O., 1995. Microseismicity and strain pattern in northwestern Greece, Tectonics, 14, 773-785.

Institute for Geology Subsurface Research of Greece and Institute Francais de Petrole (IGSR and IFP), 1966. Etude geologique de l'Epire, Paris, Technip, 306 pp.

Kanamori, H. and Anderson, D.L., 1975. Theoretical bases of some empirical relations in seismology, Bull. Seism. Soc. Am., 65, 1073-1095.

Keilis-Borok, V.I., 1959. On the estimation oft he displacement in an earthquake source and of source dimencion, Ann. Geofis., 12, 205-214.

King, G., Tselentis, A., Gomberg, J., Molnar, P., Roecker, S., Sinvhal, H., Soufleris, C. and Stock, J., 1983. Microearthquake seismicity and active tectonics of northwestern Greece, Earth Planet Sc. Lett., 66, 279-288.

King, G., Sturdy, D. and Whitney, J., 1993. The landscape geometry and active tectonics of the northwest Greece, Geol. Soc. Am. Bull., 105, 137-161.

Kiratzi, A.A., Karakaisis, G.F., Papadimitriou, E.E. and Papazachos, B.C., 1985. Seismic sourceparameter relations for earthquakes in Greece, Pageoph., 123, 28-41.

Kiratzi, A., Papadimitriou, E. and Papazachos, B.C., 1987. A microearthquake survey in the Steno dam site in northwestern Greece, Ann. Geophys., 592, 161-166.

Kumar Arjun, Kumar Ashwani, Mittal Himanshu, Kumar Ashok, Bhardwaj Rakhi, 2012. Software to Estimate Earthquake Spectral and Source Parameters, International Journal of Geosciences, 3, 1142-1149.

Martakis, N., 2003. Passive seismic tomography survey in Epirus, Ph.D. thesis, University of Patras - Faculty of Geology and Geophysics - Seismological Laboratory, 116-126, 145, 189 (In Greek).

Melis, S.N., 1992. Earthquake hazard and crustal deformation in central Greece, Phd Thesis, U.W.C.C., University.

Melis, S.N., Burton, P.W. and Brooks, M., 1995. Coseismic crustal deformation from microseismicity in the Patras area, western Greece, Geophys. J. Int., 122, 815-836.

Mercier, J., Bousquet, B., Delibasis, N., Drakopoulos, I., Keraurden, B., Lemell, F. and Sorel, D., 1972. Deformations en compression dans le quartinaire des ravages Ioniens. Donnes neotectoniques et seismiques, C. R. Acad. Sci., Paris, 275, 2307-2310.

Papazachos, C. and Kiratzi, A., 1996. A detailed study of the active crustal deformation in the Aegean and surrounding area, Tectonophysics, 253, 129-153.

Roumelioti Z., Kiratzi A., Theodoulidis N. and Papaioannou C., 2002. S-wave spectral analysis of the 1995 Kozani-Grevena (NW Greece) aftershock sequence, Journal of Seismology, 6, 219-236.

Stavroulopoulou, O., Sokos, E., Martakis, N. and Tselentis, G.-A., 2013. Earthquake relocation for Northwestern Greece using 3D crustal model; method comparison and seismotectonic interpretation, Bulletin of the Geological Society of Greece, XLVII, Proceedings of the 13th International Congress, Chania, Sept. 2013.

Taymaz, T., Jackson, J.A. and McKenzie, D., 1991. Active tectonics of the north and central Aegean Sea, Geophys. J. Int., 106, 433-490.

Tselentis, G.-A., Sokos, E., Martakis, N. and Serpetsidaki, A., 2006. Seismicity and Seismotectonics in Epirus, Western Greece: Results from a Microearthquake Survey, Bull. Seism. Soc. Am., 96(5), 1706-1717.

Underhill, J.R., 1989. Late Cenozoic deformation of the Hellenide foreland, western Greece, Geol. Soc. Am. Bull., 101, 613-634.

Waters, D., 1994. The tectonic evolution of Epirus, Northwest Greece, Ph.D. thesis, University of Cambridge, Cambridge, 248 pp. 